\title{
Redox Power Changes of Caramels and Sugar Reductones in Beer
}

\author{
Jan Savel (Corresponding author) \\ Budejovicky Budvar, N. C. \\ K. Svetle 4, C.Budejovice 37021, Czech Republic \\ Tel: 420-387-705-118Ｅ-mail: jan.savel@budvar.cz \\ Petr Kosin \\ Budejovicky Budvar, N. C. \\ K. Svetle 4, C.Budejovice 37021, Czech Republic \\ Tel: 420-387-705-123Ｅ-mail: petr.kosin@budvar.cz
}

\author{
Adam Broz \\ Budejovicky Budvar, N. C. \\ K. Svetle 4, C.Budejovice 37021, Czech Republic \\ Tel: 420-387-705-400Ｅ-mail: adam.broz@budvar.cz
}

Received: October 27, $2011 \quad$ Accepted: November 9, $2011 \quad$ Published: February 1, 2012

doi:10.5539/jfr.v1n1p132

URL: http://dx.doi.org/10.5539/jfr.v1n1p132

\begin{abstract}
Aerated or nitrogenated solutions of various sugars $(10 \% \mathrm{w} / \mathrm{w})$ in deionized water, brewing water or phosphate buffers with dichlorophenolindophenol (DCIP) addition $(10 \mathrm{mg} / \mathrm{l})$ were heated $45 \mathrm{~min}$ at $60{ }^{\circ} \mathrm{C}$ and absorbance at $520 \mathrm{~nm}\left(\lambda_{\max }\right.$ of DCIP at pH 4.6) and $610 \mathrm{~nm}\left(\lambda_{\max }\right.$ of DCIP at $\left.\mathrm{pH}>6\right)$ was measured. Reduction power of the solutions increased with the absence of oxygen, increasing $\mathrm{pH}$ value and the kind of sugar (FRU $>$ LAC,MAL, GLU $>$ SUC). Aerated solutions of various sugars were also autoclaved $\left(10 \mathrm{~min}\right.$ at $121^{\circ} \mathrm{C}$ ) and the absorbance at $420 \mathrm{~nm}$ was measured. The color of caramels from sugars was dependent on the kind of sugar (FRU> LAC,MAL, GLU>SUC), and it increased with increasing $\mathrm{pH}$ value. The formation of caramel pigments from ascorbic acid or maltose by oxidation with potassium peroxodisulfate or hydrogen peroxide was also compared. The formation of colored pigments is considered to be the mark of irreversible aging of food.
\end{abstract}

Keywords: Caramel, Reductone, Spectroscopy, Food aging, Beer, Reduction power

\section{Introduction}

Beer production comprises both aerobic and anaerobic part. Growing barley and hops, malting and starting phase of fermentation need air, while fermentation and maturation take run under anaerobic condition. Air is considered as the main reason for beer instability after filtration and filling (Briggs et al., 2004).

Although oxygen measurement during malting and brewing is well established, the determination of reduction capacity meets many difficulties (Galic \& Palic, 1994, Chapon \& Krestchmer, 2001; Moll, 2001). Nearly all the tests are carried out in the presence of oxygen. Little care is devoted to anaerobic processes taking part in aging beer.

The changes of malt and beer color during theirs production can be explained by various enzymatic or nonenzymatic mechanisms, which were generally studied in food science and industry (Friedman, 1996). Yellow, orange and brown pigments formed by thermal degradation of sugars are usually named caramels, although other authors use the term only for group of compounds, which are produced by heating reducing sugars with ammonia and its salts. Various anions influenced the color intensity, e.g. phosphate anion could catalyze the caramel formation (Agyei-Aye \& Chian, 2002).

Term melanoidins is often used for substances, which are created by reaction between sugars and $\alpha$-aminoacids 
(O’Brien \& Nursten, 1998; Perez-Magarino \& Rivero, 2000). Melanoidins are generally considered to be strong reactive substances with important technological and physiological properties (Hayashi \& Namiki, 1986; Rufian-Henares \& Morales, 2007).

The term reductone is usually used for all reducing compounds present in beer such as polyphenols, cysteine or sulfur dioxide. Sugar reductones comprise of colored or colorless substance with an endiol group. Ascorbic acid is an example of model sugar reductone, which is used for beer stabilization.

Sugar reductones undergo gradual degradation under both aerobic and anaerobic conditions. Although the process has not been completely described, the presence of simple sugar $\alpha$-dicarbonyls was proved (Bravo \& Herrera, 2008). The thermal sugar degradation products can take part in advanced glycation end products (AGE) formation (Xanthis \& Hatzitolios, 2007). The AGE breakers and inhibitors play important role in fight against modern diseases (Reddy \& Beayz, 2006).

Similar dicarbonyls can be also found in degradation products of ascorbic acid (Deutsch, 2000). Many of them gradually create colored oligomers and polymers. The final degradation products are usually distillable furfural (FF) or nonvolatile hydroxymethylfurfural (HMF) although they can be further oxidized (Lewkowski, 2001).

The majority of reports on nonenzymatic sugar browning of beverages have focused on fruit juice browning, where they are connected to natural reductone degradation. The role of oxygen in ascorbic acid degradation in fruit has been repeatedly reviewed (Garcia-Torres \& Ponagandia, 2009). Ascorbic acid can induce browning in wine in the presence of (+)-catechin in a model wine solution (Bradshaw and Prenzler, 2001).

Dehydroascorbic acid (DHA) played the most important role in this process. The efficiency of L-cysteine and sodium sulfite as antioxidant was examined in the browning of DHA solution. The browning was suppressed at higher antioxidant concentration but it increased in the presence of low concentration of those agents (Sawamura \& Nakagawa, 2000).

Both ascorbic acid and DHA provided the same species after oxidation with hydrogen peroxide. Some of resulted reaction products were more susceptible to hydrogen peroxide oxidation than ascorbic acid itself (Deutsch, 1998).

The other part of beverages browning concentrates on polyphenol oxidation. It is very difficult to distinguish between sugar or polyphenol ratio in beverage browning during its aging. Measurement of absorption spectra of beer in the VIS and UV region was used in advanced analysis of the beer color as well as in study of beer aging by differential spectrophotometry (Weeranantaphan \& Downey, 2010). The addition of various organic dyes to beer extended the capability of this method (Savel \& Kosin, 2009).

Aging beer is usually associated with irreversible oxidation process which can not be completely reversed but only slowed by reducing agents such as ascorbic acid, sulphite or dithionite. Neither yeast reductases can convert sugar or aminoacid oxidation products into initial compounds.

In the previous paper we studied caramel pigments as natural redox and alkali indicators (Savel \& Kosin, 2010). The goal of this paper is to study reductones and caramel color changes in the beer aging and find new methods and possibilities for beer redox state determination.

\section{Materials and Methods}

\subsection{Chemicals}

All chemicals including components for the preparation of phosphate buffers $(1 / 15 \mathrm{~mol} / \mathrm{l})$ were purchased from Sigma Aldrich. Sugars: D(-)-fructose (FRU), D(+)-sucrose (SUC) and D(+)-glucose (GLU) were anhydrous, $(\mathrm{D}+)$-maltose $(\mathrm{MAL})$ and $\mathrm{D}(+)$-lactose $(\mathrm{LAC})$ were monohydrates. Indicators were methylene blue (MB), thionine acetate (THIO), indigocarmine (INDC), N,N, $\mathrm{N}^{\prime}, \mathrm{N}^{\prime}$-tetramethylphenylenediamine (TMPD), dichlorophenolindophenol (DCIP), triphenyltetrazolium chloride (TTC) and methyl red sodium salt (METR). The original color of oxidized or reduced form of indicators in phosphate buffers is shown in Table 1.

\subsection{Preparation of solutions and their spectroscopy}

Conductivity of the deionized water (DI) was less than $0.2 \mu \mathrm{S} / \mathrm{cm}$, soft brewing water (BW) contained $\mathrm{Ca}^{2+}$ and $\mathrm{Mg}^{2+}$ in total content $0.7-0.8 \mathrm{mmol} / 1$, total $\mathrm{Fe}(0.1 \mathrm{mg} / \mathrm{l})$, total $\mathrm{Cu}$ (below $\left.0.05 \mathrm{mg} / \mathrm{l}\right)$. Sugar solutions contained sugars $(10 \% \mathrm{w} / \mathrm{w})$, the final concentration of indicators was $10 \mathrm{mg} / \mathrm{l}$.

Single beam spectrophotometer (Hach Lange DR 5000) equipped with cylindrical glass cells (cuvettes) and square glass or quartz cuvette, both with an optical path of $1 \mathrm{~cm}$, which were filled with liquid samples $(4 \mathrm{ml})$. Samples with high absorbance ( $>3.5$ ) were diluted appropriately. Data were obtained as an average of repeated 
experiments.

\subsection{Reductone formation from sugars}

Solutions of various sugars $(10 \% \mathrm{w} / \mathrm{w})$ in deionized or brewing water or phosphate buffers with DCIP addition $(10 \mathrm{mg} / \mathrm{l})$ were aerated or deaerated by air or nitrogen bubbling $(10 \mathrm{~min})$ in cylindrical cuvettes which were then tightly closed with rubber stoppers. The cuvettes were heated $\left(45 \mathrm{~min}, 60^{\circ} \mathrm{C}\right)$ and absorbance at $520 \mathrm{~nm}\left(\lambda_{\max }\right.$ of DCIP at $\mathrm{pH} 4.6)$ and $610 \mathrm{~nm}\left(\lambda_{\max }\right.$ of DCIP at $\left.\mathrm{pH}>6\right)$ was measured after cooling to the room temperature. The absorbance value of DCIP solution $(10 \mathrm{mg} / \mathrm{l})$ was $0.2 \mathrm{AU}$ at $\mathrm{pH} 4.6,0.5 \mathrm{AU}$ at $\mathrm{pH} 7$ and $0.6 \mathrm{AU}$ at $\mathrm{pH} 8$.

\subsection{Caramel formation from various sugars}

Aerated solutions of various sugars $(10 \% \mathrm{w} / \mathrm{w})$ in deionized water, brewing water or phosphate buffers in cylinder cuvettes were heated up to $121^{\circ} \mathrm{C}(15 \mathrm{~min})$, hold at $121^{\circ} \mathrm{C}$ for $10 \mathrm{~min}$, and cooled to $80^{\circ} \mathrm{C}(60 \mathrm{~min})$. Before opening the autoclave air was carefully introduced into the autoclave (Systec, Germany). The absorbance at $420 \mathrm{~nm}$ was measured after cooling to room temperature.

\subsection{Caramel formation by oxidation of maltose and ascorbic acid}

Maltose $(10 \% \mathrm{w} / \mathrm{w})$ or ascorbic acid $(10 \% \mathrm{w} / \mathrm{w})$ was dissolved in deionized water with hydrogen peroxide or potassium peroxodisulfate addition $(0,0.01,0.1$ and $1 \%)$, the solutions were autoclaved $\left(121{ }^{\circ} \mathrm{C}, 10 \mathrm{~min}\right)$ and the absorbance $(420 \mathrm{~nm})$ was measured after cooling.

\subsection{Visualization of caramel aging}

For the preparation of semisolid medium with or without redox indicator $(10 \mathrm{mg} / \mathrm{l})$ the agar $(0.15 \% \mathrm{w} / \mathrm{w})$ was added to the sugar solutions before autoclaving. Hot medium $(10 \mathrm{ml})$ was shortly mixed, pipetted into test tubes and transferred into refrigeration to get semisolid consistence.

Autoclaved semisolid medium containing sugar, buffer and redox indicator (alternatively) was stored for three days at room temperature and the changes of color at the top (depth $1 \mathrm{~cm}$ ), middle part and the bottom (height 1 $\mathrm{cm}$ ) of agar medium were recorded.

\section{Results and Discussion}

The reduction power of sugar solution increased during heating even at relatively low temperature. The lower the absorbance at both wavelengths after heating, the higher the reduction power was. Reduction power increased with the absence of oxygen, increasing $\mathrm{pH}$ value and the kind of sugar (FRU $>$ LAC,MAL, GLU $>\mathrm{SUC}$ ). The highest reduction power was obtained with fructose dissolved in deaerated buffer $(\mathrm{pH} 8)$, and the lowest with sucrose (pH 8) (Figure1,2,3).

Although various redox tests based on color changes of various inorganic or organic indicators have been broadly used in brewing, the product composition of these reactions was rarely mentioned. The redox reaction is supposed to be reversible e.g. ascorbic acid can be oxidized by DCIP to dehydroascorbic acid which can be again reversibly reduced (Deutsch 1998). On the other hand the dehydroascorbic acid undergoes also irreversible degradation which is not usually solved in the tests. Similarly the color indicators can be irreversibly destroyed during redox reaction.

The most of the tests mentioned in the literature are carried out in the presence of oxygen which usually influences the course of reaction, but only more sophisticated tests such as ESR can recognize the role of oxygen. Reactive oxygen species (ROS) may be formed which decreases the reduction power of tested compounds. Maillard and caramelization products take part in oxidative reactions in lager beer (Nøæddekaer and Andersen 2007).

It is difficult to distinguish the degree of sugar decomposition during redox test based only on the color change, which can be associated with oxidation of aldehydic group of sugar (Kunz and Lee 2011).

The color of caramels formed by heating in the autoclave was depended on the kind of sugar (FRU> LAC,MAL, GLU $>$ SUC), and it increased with increasing $\mathrm{pH}$ value. Color was higher in the brewing water compared to the deionized one (Figure 4).

The autoclaved solutions were diluted (1:50) with deionized water and the absorbance at $280 \mathrm{~nm}$ was measured, which was considered as a degree of sugar degradation ( $\lambda_{\max }$ of furfural and hydroxymethylfurfural). The absorbance depended on the kind of sugar (FRU $>$ LAC,MAL, GLU $>$ SUC) and it increased with increasing $p H$ value (Figure 5).

Hydroxymethylfurfural (HMF) and furfural (FF) are typical products of sugar degradation (Lewkoski, 2001). They usually serve as typical markers of their degradation under acid or alkali condition (Pereira \& Albuquerque, 
2011). Sugar dicarbonyl compounds are Maillard reaction intermediates generated by the decomposition of 3-deoxy-2-hexosulose as a direct precursor of HMF (Bravo \& Sánchez, 2002).

We suppose a reductone formation as the first step of sugar degradation, where the reduction power can paradoxically increase. In brewing technology the wort is boiled usually at $100{ }^{\circ} \mathrm{C}$, but the temperature on the brewing kettle wall can reach $120^{\circ} \mathrm{C}$ or more. During boiling the reduction power and concentration of FF or HMF increase. These compounds are reduced during fermentation but after bottling the reduction power decreases and HMF and FF concentration grow again, which is caused by sugar reductone degradation (Shimizu \& Nakamura, 2001).

Brewing process is based on reductone formation and its oxidation, where the results depend on temperature and presence of oxygen. The color of caramels formed from maltose and ascorbic by oxidation with potassium peroxodisulfate during heating increased with increasing concentration of oxidation agent even at low $\mathrm{pH}$ value of ascorbic acid solution. The color of caramel pigments formed from ascorbic acid was higher than that of maltose, where oxidation with potassium peroxodisulfate was efficient, whereas hydrogen peroxide provided only slightly colored solution (Figure 6).

Ascorbic acid can be considered as a sugar reductone, of which degradation pathway is nowadays known in the substantial steps, but there is still much unclear. Many of the degradations products e.g. dehydroascorbic acid or diketogulonic acid show more efficient reducing effect than ascorbic acid itself, they can bind oxygen and therefore they are classified to antioxidants (Deutsch, 1998). Sugars and ascorbic acid degradation in the presence phenylalanine provided similar degradation products (Seck \& Crouzet, 1981). The strong reductones are also formed during acid hydrolysis of sugars.

The strongest reducing effect is usually attributed to simple triose reductone, which was prepared by alkali hydrolysis of glucose (Abe \& Horii, 1986). The oxidation of sugar reductone by oxygen in air is usually responsible for the yellow and brown pigments from sugars or ascorbic acid. Coincidence between sugars and ascorbic acid during its degradation was also found (Rojas \& Gerschenson, 2001).

We observed the overoxidation of such pigments but the process needed high concentration of hydrogen peroxide. The cocktail of various degradation products including $\alpha$-hydroxycarbonyl and $\alpha$-dicarbonyl was found after oxidation of various sugars with potassium peroxodisulfate in acid or alkali environment (Novotny \& Cejpek 2007, 2008).

The spontaneous hydrogen peroxide formation was estimated in naturally buffered drinking water with ascorbic acid in the presence of various metals with various buffering capacity (Jansson \& Lindquist, 2005). Metals can also take part in hydrogen peroxide decomposition (Fenton reaction). Ascorbic acid/Cu(II) system serve as a source of oxygen free radicals (OFR) in many tests e.g. in studies searching for antioxidants and medicines (Rahbar \& Figarolla, 2003). Hydrogen peroxide formation followed by its degradation was proved during beer aging (Chapon \& Chapon, 1979). Organic radicals were formed during beer aging (Andersen \& Skibsted, 1998).

The negative oxygen concentration gradient occurs from the top to the bottom in the semisolid agar layer (Table 2). The oxygen gradient in the semisolid medium enables the observation of the spontaneous oxidation of reductone. The sharp interface between methylene blue or thionine acetate and the rest of semisolid medium shows the zone of oxidizied dye caused by oxygen. The brown pigment formation in the top layer is probably caused by strong oxidation of yellow maltose caramels.

Thionine was newly used for the visualization of beer oxidation by air. This test is similar to methylene blue test, but the thionine is easily decolorized. The formation of ROS from oxygen is supposed to reoxidize reduced form of the dye.

Brown top layer in the case of INDC is caused by irreversible oxidative degradation of INDC together with reductone oxidation while the yellow color at the bottom of the test tube is associated with reversible reduction of INDC in the absence of oxygen. TMPD or DCIP were reduced to their colorless forms even in the presence of oxygen. On the other hand INDC undergoes air oxidation which is connected to its splitting into colorless isatin (Kettle \& Clark, 2004, Savel \& Kosin, 2009).

The red color of reduced TTC could be caused by strong reductive species such as superoxide radical formed from oxygen or by the strong reductone formation. Another example is irreversible degradation of methyl red, which can be achieved by heating it with fructose in phosphate buffer $(\mathrm{pH} 4.6)$ above $110^{\circ} \mathrm{C}$ although methyl red solution without fructose remains red. The irreversible degradation of MR in the absence of air was observed before (Savel \& Kosin, 2009). Colored pigments from sugars can be regarded as compounds with indicator properties (Savel \& Kosin, 2010). 
DCIP or TMPD can be overoxidized by strong oxidation agents e.g. potassium peroxodisulfate, while methyl red overoxidized or overreduced by strong oxidative or reductive agent was observed before (Savel \& Kosin, 2009). Common feature of such irreversible/reversible processes can be expressed as single mechanism of aging (Figure 7).

We suppose that degradation of sugar forms chain of these simple reversible/irreversible reactions. In the case of ascorbic acid the final product furfural is formed mainly under anaerobic condition while under aerobic condition the oxidation continues up to 2-furoic acid and 3-hydroxy-2-pyrone (Yuan \& Chen, 1998; Shi \& Zhan, 2007).

In aerobic processes the oxidation agent is usually oxygen, which can provide oxygen radicals while sugar reductone ascorbic acid gives ascorbyl radical. We suppose that it might take part in MR degradation. The radical formation maintains the rapid course of reaction in several steps. The sugar oxidation by radical initiators and sugar radical formation has been also described (Luo \& Qi, 2001).

In beer production the color of caramels can increase e.g. during wort boiling or decrease with subsequent oxidative degradation under aerobic condition (Savel \& Kosin, 2009). Which of the both processes prevails depends probably on oxygen concentration.

The formation of colored pigments is considered to be the mark of irreversible aging of food and there is little evidence of reversibility of this reaction. In the case of sugar the main proof of irreversibility is the presence of final degradation products such as furfural and HMF which can be only partially reversible reduced to furfurylalcohol or hydroxymethylfurfurylalcohol but not to the original sugar. Reversible color changes of synthetic indicators is therefore good marker of reductone aging, providing that strong reductive agent such as yeast dehydrogenase or strong oxidative agent e.g. hydrogen peroxide are not present. On the other hand the irreversible changes of indicators show the presence of strong oxidative or reductive species.

The thermal degradation of dry sugar is connected to reductone formation (Savel a Kosin, 2009). The recent studies have confirmed coincidence between thermal fructose or sucrose degradation and HMF formation (Lee \& Thomas, 2011).

\section{Conclusion}

Sugars dissolved in deionized or brewing water or phosphate buffers ( $\mathrm{pH} 4.6-8$ ) undergo spontaneous degradation. The sugar degradation is associated with reductone and caramel formation and solution browning.

Reduction power of the reductones depends on kind of sugar, $\mathrm{pH}$ value, temperature, heating time and the presence of oxygen.

Anaerobic or aerobic sugar degradation is connected with UV active $\left(\lambda_{\max }=280 \mathrm{~nm}\right)$ compounds formation, probably furfural and hydroxymethylfurfural and their derivates.

Caramel pigments were also obtained by ascorbic acid or maltose oxidation with potassium peroxodisulfate or hydrogen peroxide.

Two steps oxidation mechanism of sugars or reductones degradation based on hydrogen peroxide formation followed by Fenton reaction is supposed.

Reversible/irreversible mechanism was designed to explain redox changes during aging.

Oxygen gradient in semisolid sugar medium containing redox indicators is useful tool to study sugar decomposition.

\section{References}

Abe, Y., Horii, H., Taniguchi, S., Yamabe, S., \& Ninato, T. (1986). A theoretical study on the oxidation mechanism of triose reductone in reference to L-ascorbic acid. Canadian Journal of Chemistry, 64(2), 360-365. http://dx.doi.org/10.1139/v86-059

Agyei-Aye, K., Chian, M. X., Lauterbach, J. H., \& Moldoveanu, S. C. (2002). The role of anion in the reaction of reducing sugars with ammonium salts. Carbohydrate Research, 337(21-23), 2273-2277. http://dx.doi.org/10.1016/S0008-6215(02)00221-5

Andersen, M. L., \& Skibsted, L. H. (1998). Electron spin resonance spin trapping identification of radicals formed during aerobic forced aging of beer. Journal of Agricultural and Food Chemistry, 46(4), 1272-1275. http://dx.doi.org/10.1021/jf9708608

Bradshaw, M. P., Prenzler, P. D., \& Scollary, G. R. (2001). Ascorbic acid-induced browning of (+)-catechin in a 
model wine system. Journal of Agricultural and Food Chemistry, 49(2), 934-939. http://dx.doi.org/10.1021/jf000782f

Bravo, A., Sánchez, B., Scherer, E., Herrera, J., \& Rangel-Aldao, R. (2002). $\alpha$-dicarbonylic compounds as indicators and precursors of flavor deterioration during beer aging. Technical Quarterly of Master Brewers Association of the Americas. 39(1), 13-23.

Bravo, A., Herrera, J. C., Scherrera, J. C., Scherer, E., Ju-Nam, Y., Rübsam, H., Madrid, J., Zufall, C., \& Rangel-Aldao. (2008). Formation of dicarbonyl compounds in beer during storage of pilsner. Journal of Agricultural and Food Chemistry, 56(11), 4134-4144. http://dx.doi.org/10.1021/jf703696p

Briggs, D. E., Boulton, Ch. A., Brookes, P. A., \& Stevens, R. (2004). Brewing science and practice. (1st. ed.). London: CRC Press. ISBN 13: 978-0849325472.

Chapon, L., \& Chapon, S. (1979). Peroxidatic step in oxidation of beers. Journal of the American Society of Brewing Chemists, 37(2), 96-104.

Chapon, L., \& Kretschmer, K. F. (2001). Über die Bedeutung der reduzierenden Kraft bei hellen Bieren. Monatsschrift für Brauwissenschaft, 54(9/10), 185-198.

Deutsch, J. C. (1998). Ascorbic acid oxidation by hydrogen peroxide. Analytical Biochemistry, 255(1), 1-7. http://dx.doi.org/10.1006/abio.1997.2293

Deutsch, J. C. (2000). Review. Dehydroascorbic acid. Journal of Chromatography A, 881(1-2): 299-307. http://dx.doi.org/10.1016/S0021-9673(00)00166-7

Friedman, M. (1996). Food browning and its prevention: An overview. Journal of Agricultural and Food Chemistry, 44(3), 631-653. http://dx.doi.org/10.1021/j9950394r

Galic, K., Palic, A., \& Cikovic, N. (1994). On the redox potential in brewing process - a review. Monatsschrif. für Brauwissenschaft, 47(4), 124-128.

García-Torres, R., Ponagandia, N. R., Rouseff, R. M., \& Goodrich-Schneider, J. I. (2009). Effects of dissolved oxygen in fruit juices and methods of removal. Comprehensive Reviews in Food Science and Food Safety, 8(4), 409-423. http://dx.doi.org/10.1111/j.1541-4337.2009.00090.x

Hayashi, T., \& Namiki, M. (1986). Role of sugar fragmentation in early stage browning amino-carbonyl reaction of sugar with amino acid. Agricultural and Biological Chemistry, 50(8), 1965-1970. http://dx.doi.org/10.1271/bbb1961.50.1965

Jansson, P. J., Lindquist, Ch., \& Nordström, T. (2005). Iron prevents ascorbic acid (vitamin C) induced hydrogen peroxide accumulation in copper contaminated drinking water. Free Radical Research, 39(11), 1233-1239. http://dx.doi.org/10.1080/10715760500249861

Kettle, A. J., Clark, B. M., \& Winterbourn, Ch. C. (2004). Superoxide converts indigo carmine to isatin sulfonic acid. Journal of Biological Chemistry, 279(18), 18521-18525. http://dx.doi.org/10.1074/jbc.M400334200

Kunz, T., Lee, E. J., Schiwek, V., Seewald, T. \& Methner, F. (2011). Glucose - a reducing sugar? Reducing properties of sugars in beverages and food. BrewingScience, 64(6/7), 61-67.

Lee, J. W., Thomas, L. C., Jerrell, J., Feng, H., Cadwallader, K. R., \& Schmidt, S. J. (2011). Investigation of thermal decomposition as the kinetic process that causes the loss of crystalline structure in sucrose using a chemical analysis approach (Part II). Journal of Agricultural and Food Chemistry, 59(2), 702-712. http://dx.doi.org/10.1021/jf104235d

Lewkowski, J. (2001). Synthesis, chemistry and applications of 5-hydroxymethylfurfural and its derivates. Arkivoc, 2001 (i), 17-54.

Luo, G., Qi, D., Zheng, Y., Mu, Y., Yan, G., Yang, T., \& Shen, J. (2001). ESR studies on reaction of saccharide with the free radicals generated from xanthine oxidase/hypoxanthine system containing iron. FEBS Letters, 492(1-2), 29-32. http://dx.doi.org/10.1016/S0014-5793(01)02226-8

Moll, M. (2001). Determination of antioxidants in brewing. Part 1 Chemical methods. Monatsschrift für Brauwissenschaft, 54(1/2), 28-32.

Nøæddekaer, T. V., \& Andersen, M. L. (2007). Effects of Maillard and caramelization products on oxidative reactions in lager beer. Journal of the American Society of Brewing Chemists, 65(1), 15-20.

Novotný, O., Cejpek, K., \& Velíšek, J. (2007). Formation of $\alpha$-hydroxycarbonyl and $\alpha$-dicarbonyl compounds during degradation of monosaccharides. Czech Journal of Food Science, 25(3): 119-130. 
Novotný, O, Cejpek, K., \& Velíšek, J. (2008). Formation of carboxylic acids during degradation of monosaccharides. Czech Journal of Food Science, 26(2), 117-131.

O'Brien, J., Nursten, H. E., Crabbe M. J. C., \& Ames, J. M. (1998). The Maillard reaction in foods and medicine. Royal Soc. Chem., Cambridge, UK. 1998. ISBN 0-85404-733-6. http://dx.doi.org/10.1533/9781845698447

Perez-Magarino, S., Rivero, M. D., \& Gonzales-Sanjose, M. L. (2000). Melanoidins in brown alcoholic beverages. Czech Journal of Food Science, 18 (spec. no.), 108-109.

Pereira, V., Albuquerque, F. M., Ferreira, A. C., Cacho, J., \& Marques, J.C. (2011). Evolution of 5-hydroxymethylfurfural (HMF) and furfural (F) in fortified wines submitted to overheating conditions. Food Research International, 44(1), 71-76. http://dx.doi.org/10.1016/j.foodres.2010.11.011

Rahbar, S., \& Figarola, J. L. (2003). Novel inhibitors of advanced glycation endproducts. Archives of Biochemistry and Biophysics, 419(1), 63-79. http://dx.doi.org/10.1016/j.abb.2003.08.009

Reddy, V. P., \& Beayz, A. (2006). Inhibitors of the Maillard reaction and AGE breakers as therapeutics for multiple diseases. Drug Discovery Today, 11(13-14), 646-654. http://dx.doi.org/10.1016/j.drudis.2006.05.016

Rojas, A. M., \& Gerschenson, L .N. (2001). Ascorbic acid destruction in aqueous model systems: an additional discussion. Journal of Science and Food Agricultural, 81(15), 1433-1439. http://dx.doi.org/10.1002/jsfa.961

Rufian-Henares, J. A., \& Morales, F. J. (2007). Angiotensin-I converting enzyme inhibitory activity of coffee melanoidins. Journal of Agricultural and Food Chemistry, 55(4), 1480-1485. http://dx.doi.org/10.1021/jf062604d

Savel, J., Kosin, P., \& Broz, A. (2009). New oxidation destructive analysis (NODA). Monatsschrift für Brauwissenschaft, 62(7/8), 155-163.

Savel, J., Kosin, P., \& Broz, A. (2010). Anaerobic and aerobic beer aging. Czech Journal of Food Science, 28(1), $18-26$.

Sawamura, M., Nakagawa, T., Katsuno, S., Hamaguchi, H., \& Ukeda, H. (2000). The effects of antioxidants on browning and on degradation products caused by dehydroascorbic acid. Journal of Food Science, 65(1), 20-23. http://dx.doi.org/10.1111/j.1365-2621.2000.tb15949.x

Seck, S., \& Crouzet, J. (1981). Formation of volatile compounds in sugar-phenylalanine and ascorbic acid-phenylalanine model systems during heat treatment. Journal of Food Science, 46(3), 790-793. http://dx.doi.org/10.1111/j.1365-2621.1981.tb15349.x

Shi, Y., Zhan, X., Ma, L., Lin, B., Li, L., Li, C, \& He, N. (2007) Compressed oxygen in drug stability experiments. Chemical Pharmaceutical Bulletin, 55(1), 87-91. http://dx.doi.org/10.1248/cpb.55.87

Shimizu, C, Nakamura, Y., Miyai, K., Araki, S., Takashio, M., \& Shinotsuka, K. (2001). Factors affecting 5 -hydroxymethyl furfural formation and stale flavor formation in beer. Journal of the American Society of Brewing Chemists, 59(2), 51-58.

Weeranantaphan, J., \& Downey, G. (2010). Identity confirmation of a branded, fermented cereal produkt by UV spectroscopy: A feasibility study involving a trappist beer. The Journal of the Institute of Brewing 116(1), 56-61.

Xanthis, A., Hatzitolios, A., Koliakos, G., \& Tatola, V. (2007). Advanced glycosylation end products and nutrition - a possible relation with diabetic atherosclerosis and how to prevent it. Journal of Food Science, 72(8), 125-129. http://dx.doi.org/10.1111/j.1750-3841.2007.00508.x

Yuan, J. P., \& Chen, F. (1998). Degradation of ascorbic acid in aqueous solution. Journal of Agricultural and Food Chemistry, 46(12), 5078-5082. http://dx.doi.org/10.1021/jf9805404 
Table 1. Color changes of redox indicators in phosphate buffers

\begin{tabular}{|c|c|c|c|c|c|c|}
\hline & \multicolumn{3}{|c|}{ Reduced form } & \multicolumn{3}{c|}{ Oxidized form } \\
\hline Indicator & $\mathrm{pH} 4.6$ & $\mathrm{pH} 7$ & $\mathrm{pH}$ & $\mathrm{pH} 4.6$ & $\mathrm{pH} 7$ & $\mathrm{pH} 8$ \\
\hline MB & colorless & colorless & colorless & blue & blue & blue \\
\hline THIO & colorless & colorless & colorless & blue & blue & blue \\
\hline INDC & colorless & colorless & colorless & blue & blue & blue \\
\hline TMPD & colorless & colorless & colorless & blue & blue & blue \\
\hline DCIP & colorless & colorless & colorless & red & blue & blue \\
\hline TTC & red & red & red & colorless & colorless & colorless \\
\hline METR & red & yellow & yellow & red & yellow & yellow \\
\hline
\end{tabular}

Table 2. Color changes of redox indicators in the layer of autoclaved semisolid medium during storage in the air (three days at $25^{\circ} \mathrm{C}$ )

\begin{tabular}{|c|c|c|c|c|c|c|}
\hline & \multicolumn{3}{|c|}{ Maltose, $\mathrm{pH} 7$} & \multicolumn{3}{c|}{ Sucrose, $\mathrm{pH} 7$} \\
\hline Indicator & Top & Middle & Bottom & Top & Middle & Bottom \\
\hline none & brown & yellow & yellow & colorless & colorless & colorless \\
\hline MB & blue & yellow & yellow & blue & blue & blue \\
\hline THIO & blue & yellow & yellow & blue & blue & blue \\
\hline INDC & brown & blue & yellow & colorless & blue & blue \\
\hline TMPD & brown & yellow & yellow & colorless & colorless & colorless \\
\hline DCIP & brown & yellow & yellow & colorless & blue & colorless \\
\hline TTC & brown & red strip & yellow & colorless & pink strip & colorless \\
\hline
\end{tabular}

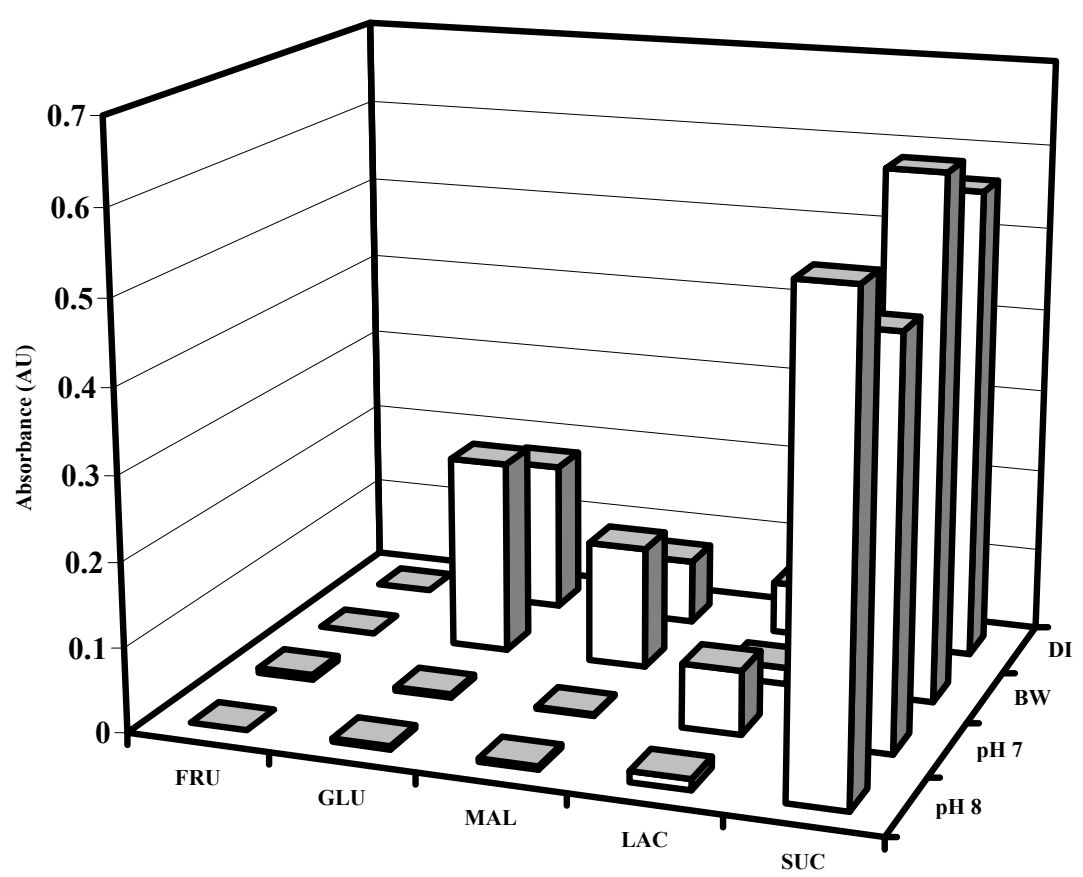

Figure 1. Absorbance $(610 \mathrm{~nm})$ of various sugars $(10 \% \mathrm{w} / \mathrm{w})$ with DCIP $(10 \mathrm{mg} / \mathrm{l})$ dissolved in nitrogenated deionized (DI), brewing (BW) water and phosphate buffers ( $\mathrm{pH} 7$ and 8) after 45 min pasteurization at $60{ }^{\circ} \mathrm{C}$,

FRU - fructose, GLU - glucose, MAL - maltose, LAC - lactose, SUC - sucrose 


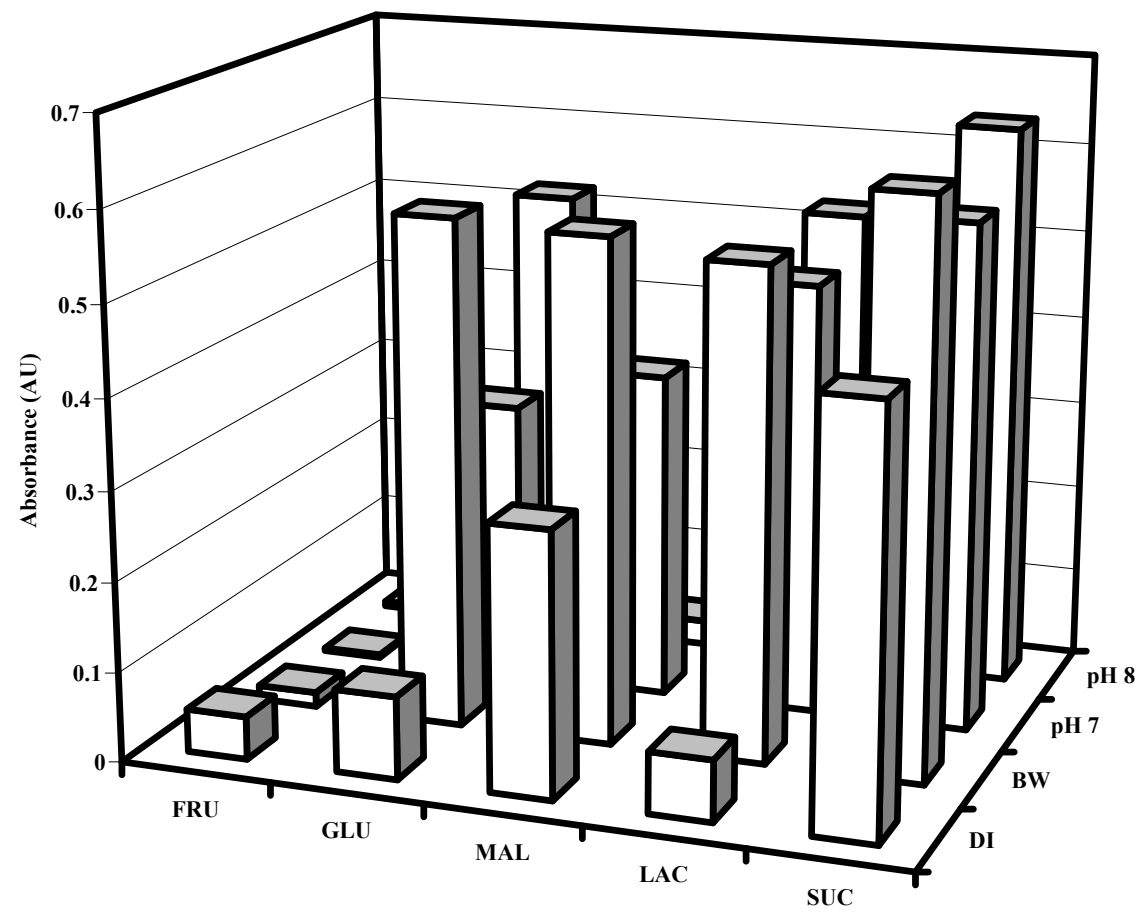

Figure 2. Absorbance $(610 \mathrm{~nm})$ of various sugars $(10 \% \mathrm{w} / \mathrm{w})$ with DCIP $(10 \mathrm{mg} / \mathrm{l})$ dissolved in aerated deionized (DI), brewing (BW) water and phosphate buffers ( $\mathrm{pH} 7$ and 8 ) after 45 min pasteurization at $60{ }^{\circ} \mathrm{C}$,

FRU - fructose, GLU - glucose, MAL - maltose, LAC - lactose, SUC - sucrose

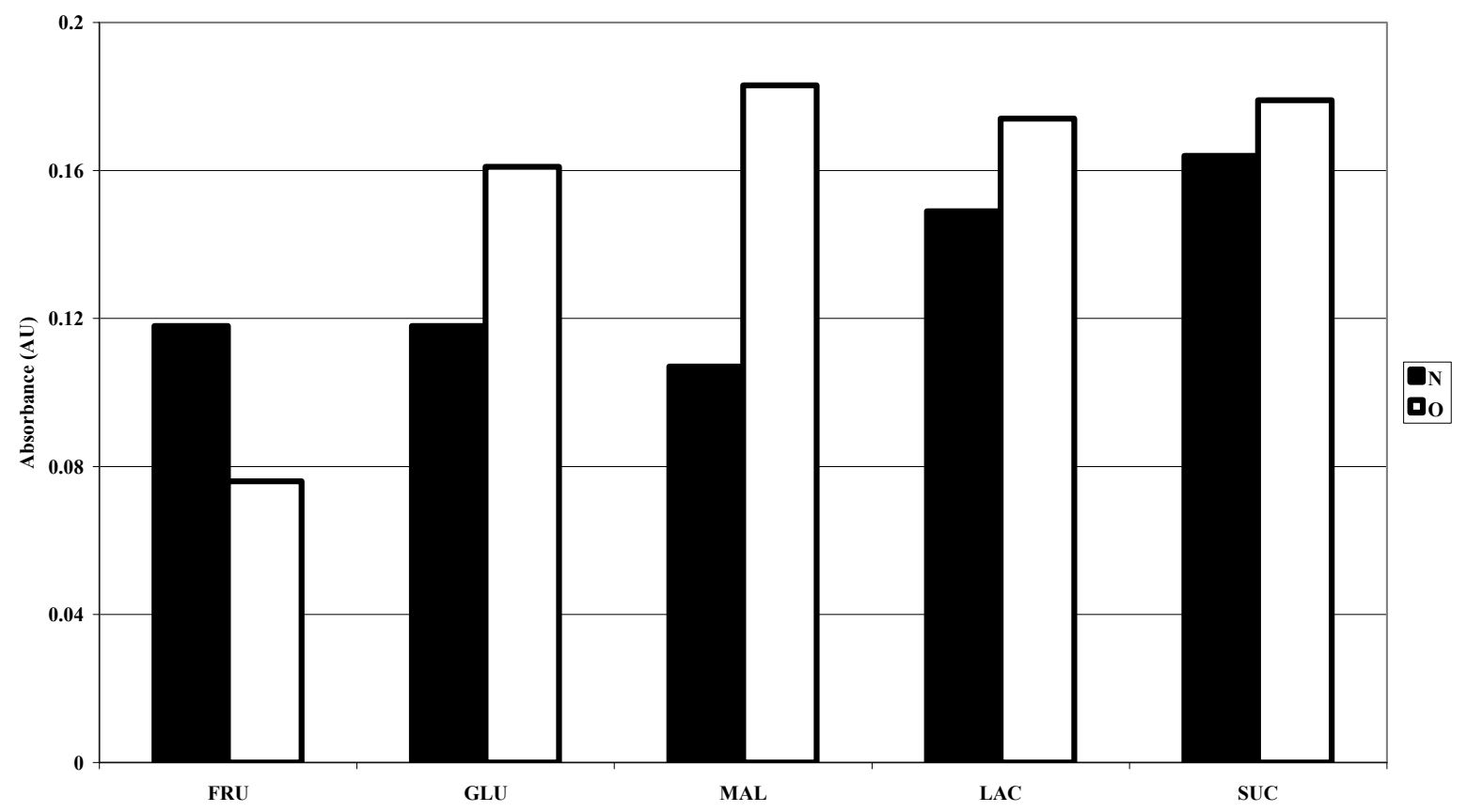

Figure 3. Absorbance $(520 \mathrm{~nm})$ of various sugars $(10 \% \mathrm{w} / \mathrm{w})$ with DCIP $(10 \mathrm{mg} / \mathrm{l})$ dissolved in nitrogenated $(\mathrm{N})$ or aerated $(\mathrm{O})$ phosphate buffer $(\mathrm{pH} 4.6)$ after $45 \mathrm{~min}$ pasteurization at $60^{\circ} \mathrm{C}, \mathrm{FRU}$ - fructose, GLU - glucose, $\mathrm{MAL}$ - maltose, LAC - lactose, SUC - sucrose 


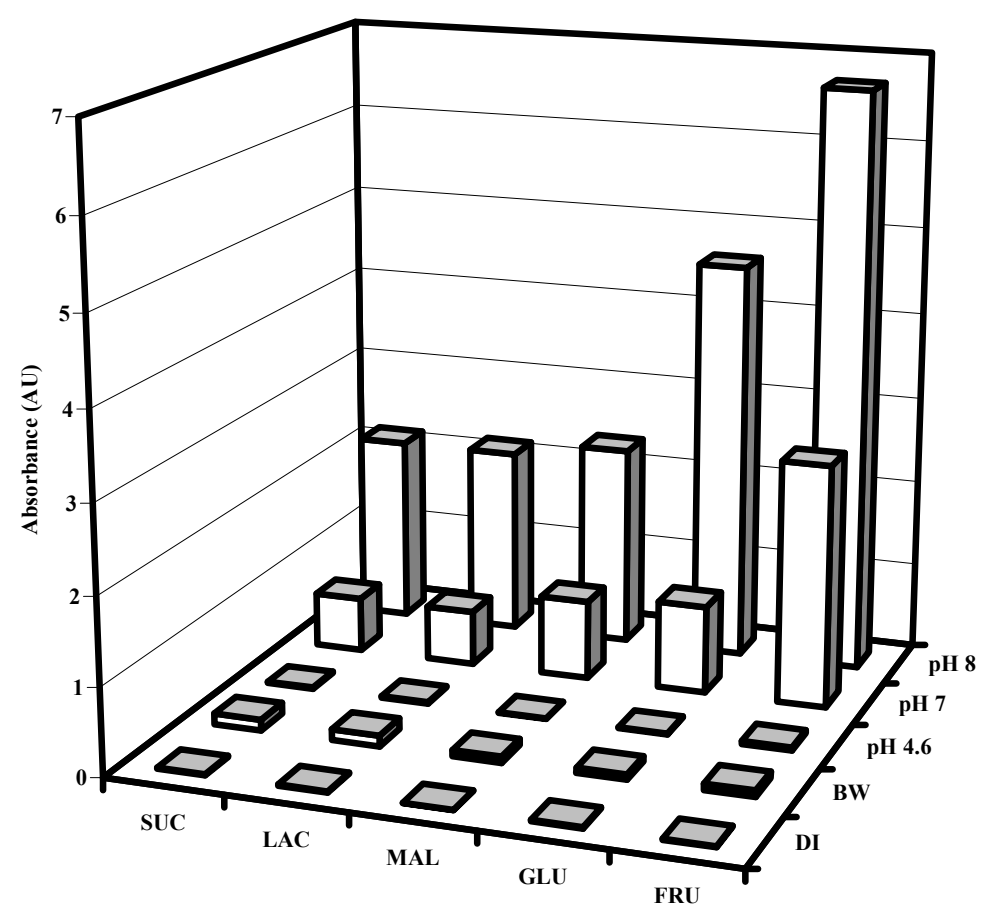

Figure 4. Absorbance (420 nm) of various sugars $(10 \% \mathrm{w} / \mathrm{w})$ dissolved in aerated deionized (DI), brewing (BW) water and phosphate buffer $(\mathrm{pH} 4.6,7$ and 8$)$ after autoclaving $\left(10 \mathrm{~min}, 121^{\circ} \mathrm{C}\right)$

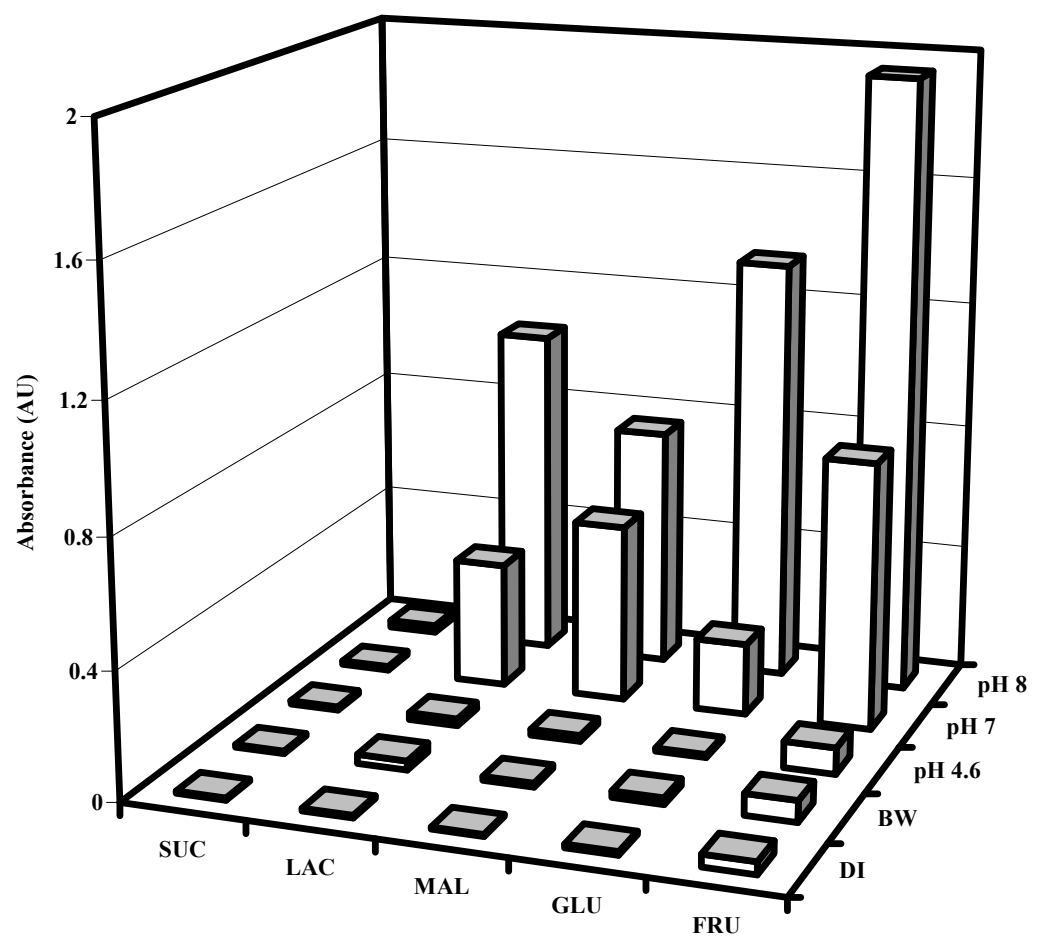

Figure 5. Absorbance $(280 \mathrm{~nm})$ of various sugars $(10 \% \mathrm{w} / \mathrm{w})$ dissolved in aerated deionized (DI), brewing (BW) water and phosphate buffer $(\mathrm{pH} 4.6,7$ and 8$)$ after autoclaving $\left(10 \mathrm{~min}, 121^{\circ} \mathrm{C}\right)$ and dilution $(1: 50)$ 


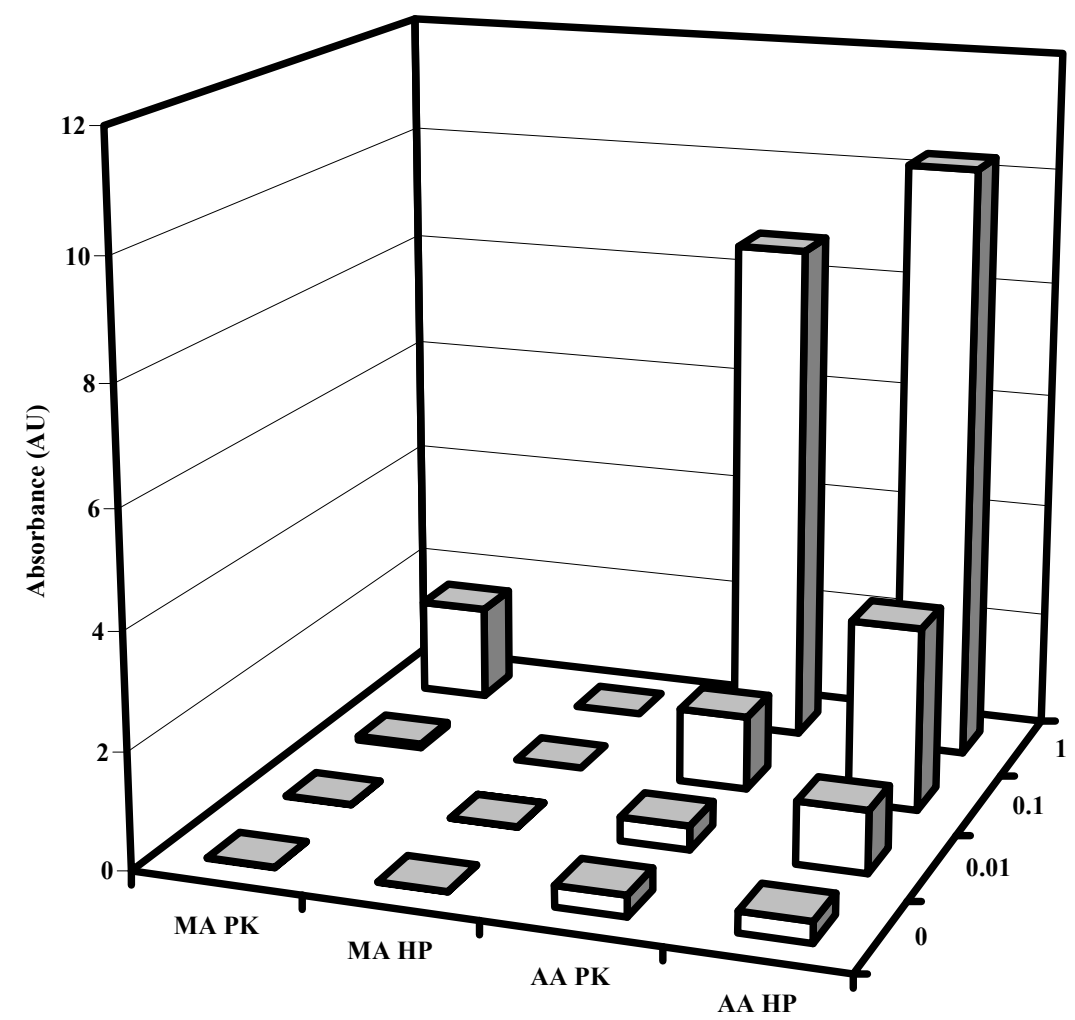

Figure 6. Absorbance (420 nm) of autoclaved solutions of maltose (MA, $10 \%$ ) or ascorbic acid (AA, $10 \%$ ) dissolved in aerated deionized water with potassium peroxodisulfate (PK, $0-1 \%$ ) or hydrogen peroxide (HP, 0 $-1 \%)$

\section{SOURCE COMPOUND}

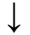

irreversible process

e.g. sugar degradation or indicator synthesis

\section{REDOX INDICATOR or \\ SUGAR REDUCTONE}

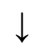

$$
\mathrm{A}_{\text {ox }}+\text { ne- }=\mathrm{A}_{\text {red }}
$$

irreversible product $\leftarrow$ (reversible redox pair) $\rightarrow$ irreversible product overoxidation, polymerization overreduction, polymerization

Figure 7. Mechanism of reversible/irreversible redox changes during sugar degradation 